\title{
BIOSORPTION OF CHROMIUM IONS BY CALCIUM ALGINATE NANOPARTICLES
}

\author{
ASMA SADIQ ${ }^{\prime *}$, ANITA CHOUBEY', AND A.K.BAJPAI \\ ${ }^{I}$ Department of Chemistry Govt. M.L.B. Girls (P.G) Autonomous College, Bhopal MP \\ ${ }^{2}$ Bose Memorial Research Laboratory Department of Chemistry Government Autonomous Science College Jabalpur MP
}

\section{ABSTRACT}

The objectives of the present work include synthesis of nanoparticles of calcium alginate by emulsion crosslinking method, their characterization by techniques such as FTIR, scanning electron microscopy (SEM), XRD, particle size and surface charge analysis, and study of removal of chromium ions from synthetic aqueous solutions. In order to study the effect of various factors like adsorbent dose, initial metal ion concentration, $\mathrm{pH}$ and temperature on the adsorption of chromium ions from water, a series of batch sorption experiments were conducted. The obtained results were analysed by Langmuir and Freundlich isotherm models and it was found that the adsorption of chromium more precisely follows Langmuir absorption isotherm. The metal ion removal capacity of the nanoparticles was found to depend on the chemical composition of the adsorbent, concentration of the metal ion solution, $\mathrm{pH}$ and temperature of the medium and speed of the suspension from wastewater before disposal.

Keywords: Chromium, alginate, nanoparticles, adsorption, emulsion cross linking.

\section{INTRODUCTION}

Water pollution is one of the most serious ecological threats the society is facing today. Pure water is not easily available to all. Deprived sections of the society consume contaminated water and take illness periodically. Water pollution mainly occurs due to organic and inorganic wastages, sediments, radioactive materials, effluents, sewages and heavy metals. Among these pollutants, contribution of heavy metals is of major concern because of their toxicity, bioaccumulation, persistence and non-biodegradable nature and large scale extraction of metal released more various industries and high concentrations of heavy metals in rivers discharged from metal extractions $[1,2]$. The removal of toxic metal ions from waste water is an important and widely researched area. One of the toxic heavy metals that have been of major environmental concern in waste water treatment is chromium [3, 4].

Chromium is an essential nutrient for plants and animals metabolism. However, the increasing accumulation of chromium in the environment from industrial outputs has caused great concern. Chromium contaminated waste waters can originate from dyes and pigment manufacturing, wood preserving, electroplating and leather tanning industries. In India also, there are a large number of tanneries scattered all over the country and nearly $80 \%$ of these tanneries are engaged in the chrome tanning processes. Most of them discharge untreated wastewater into the environment. The current pattern of industrial activity alters the natural flow of materials and introduces novel chemicals into the environment $[5,6]$.

Heavy metals are those metals that have density more than $5 \mathrm{~g} / \mathrm{mL}$. Water contamination with heavy metals is an important problem in the current world [7]. Moreover, several studies have reported that the uptake of heavy metals by organisms depends on the free metal ion concentration rather than the total metal concentration in solution. In fact, free metal ion concentration ultimately determines the bioavailability and toxicity of heavy metal, owing to better correlations between metal uptake and the concentration of free metal ion or labile metals $[8,9]$. Metal ions are non-biodegradable in nature and their intake at a certain level is toxic [10]. According to the World Health Organization, the metals of most immediate concern are cadmium, chromium, cobalt, copper, lead, nickel, mercury, zinc and arsenic. $\mathrm{Hg}, \mathrm{Cr}$, and $\mathrm{Pb}$ are called the big three highly toxic [11] while $\mathrm{Cr}, \mathrm{Cu}, \mathrm{Zn}$ are neurotoxin metals [12-14].

Chromium exists in oxidation states from +2 to +6 , but only two states, the trivalent and hexavalent, are of environmental significance. Trivalent chromium, $\mathrm{Cr}$ (III), is considered to be a trace element that is essential for the functioning of living organisms [15], but at high concentration it can be dangerous to health as it can co-ordinate with organic compounds which in turn leads to inhibition of some metallo-enzyme systems. Hexavalent chromium which is primarily present in the form of chromate $\left(\mathrm{CrO}_{4}^{2-}\right)$ in alkaline and dichromate $\left(\mathrm{Cr}_{2} \mathrm{O}_{7}{ }^{2-}\right)$ in acidic environment poses significantly higher levels of toxicity than the other valence states [16].

The selection of an effective and economic adsorbent in removal of toxic metals ion requires consideration of both conventional and non-conventional materials such as activated carbons [17], metal oxides [18], cotton [19], jute fibres [20], bamboo pulp [21-22], etc. In the last few years, biopolymers have attracted scientific community for a number of reasons. They are widely available, environmentally viable and capable of lowering transition metal ion concentration to parts per billion (ppb) concentrations [23]. Another attractive feature of these biopolymers is that they possess a number of functional groups such as hydroxyls and amines to which metal ion can bind either by physical or by chemical adsorption. A more significant aspect is the metal ion recovery that may be done by simply exposing the material to an aqueous acid solution.

The recommended limit of $\mathrm{Cr}(\mathrm{VI})$ in potable water is only $0.05 \mathrm{mg} / \mathrm{L}$. Conventional methods for removing $\mathrm{Cr}(\mathrm{VI})$ ions from industrial wastewater include reduction [24], reduction followed by chemical precipitation, and adsorption on activated carbon [25-27], solvent extraction [28], freeze separation, reverse osmosis [29], ion exchange [30] and electrolytic methods [31].

The preceding discussion has motivated the authors to undertake the present study that aims at investigating the removal of $\mathrm{Cr}$ (VI) ions from aqueous solution by adsorption onto the nanoparticles of calcium alginate prepared by emulsion crosslinking of sodium alginate by calcium chloride.

\section{EXPERIMENTAL PART}

\subsection{Materials}

Biopolymer sodium alginate was of high purity grade and purchased from local chemical suppliers (Merck India, Mumbai, India). Calcium chloride was used as crosslinking agent. Silicon oil (Aldrich, USA) viscosity 10,000 (cSt) (at $25^{\circ} \mathrm{C}$ ) was used as an oil phase for preparing the suspension. Chromium (potassium dichromate salt) and other chemicals were of high purity grade and throughout the work the double distilled water was used for making solutions.

2.2 Methods

2.2.1 Preparation of Nanospheres

A known solution of sodium alginate was stirred on magnetic stirrer for about $20 \mathrm{~min} .3 \mathrm{~mL}$ mixture of calcium chloride and silicon oil was added dropwise into the suspension of Sodium alginate with the help of a syringe under constant stirring. Calcium alginate nanoparticles were prepared, washed with acetone and then benzene and dried at $80{ }^{\circ} \mathrm{C}$ for $48 \mathrm{~h}$.

\subsubsection{Adsorption Experiments}

The adsorption was carried out by the batch contact method as described elsewhere [32]. Firstly, the stock solution of chromium ions was prepared by dissolving $0.6 \mathrm{~g}$ of dichromate in 1 litre distilled water. In to $6 \mathrm{~mL}$ of dilute stock solution of chromium ions, $100 \mathrm{mg}$ of swollen nanospheres of calcium alginate were added as adsorbent. The suspension was shaken in a rotary shaker (Tempstar, India) for $4 \mathrm{~h}$ which was found to be a sufficient time to attain equilibrium adsorption. After shaking is over, $3 \mathrm{~mL}$ supernatant was mixed with $1 \mathrm{~mL}$ the reagent $\left(\mathrm{NH}_{3}\right.$ solution) and the amount of chromium was assayed spectrophotometrically by measuring the absorbance at $540 \mathrm{~nm}$. The concentration of chromium was estimated using a calibration plot drawn for chromium solution varying in the range of 0.1 to $10 \mathrm{ppm}$. The amount of adsorbed $\mathrm{Cr}$ (VI) (mg/g) was calculated by the following mass balance equation, 


$$
\text { Adsorbed amount }(\mathrm{mg} / \mathrm{g})=(C i-C f) V / m
$$

where $\mathrm{C}_{\mathrm{i}}$ and $\mathrm{C}_{\mathrm{f}}$ being the initial and final concentrations of chromium solution $(\mathrm{mg} / \mathrm{mL})$. $\mathrm{V}$ being the volume of adsorbate solution and $\mathrm{m}$ is the weight of swollen nanospheres (adsorbent).

\subsubsection{Characterization}

2.2.3.1 FTIR spectral analysis

The presence of functional groups of the constituent biopolymer in the nanoparticles was confirmed by FTIR spectral analysis (Shimadzu, 1800).

2.2.3.2 Scanning electron microscopy (SEM)

In order to study morphology of the prepared nanospheres, the SEM analysis of the microspheres surface was carried out (STEREO SCAN, 430, Leica SEM, USA).

2.2.3.3 Particle Size Analysis

The size of the prepared nanospheres was determined by a particle size analyser (Fritsch Particle Sizer, Germany).

2.2.3.4 Surface Charge Analysis

As the nanospheres are composed of anionic alginate, their surface bears a charge that may be determined by EMF (electromotive force, $\mathrm{mV}$ ) measurements. In order to determine the magnitude of surface charge, $1 \mathrm{~g}$ nanospheres were allowed to swell in $25 \mathrm{~mL}$ of distilled water and the charge developed over the surface was measured by $\mathrm{pH} / \mathrm{EMF}$ meter (Systronics pH system 362, Ahmadabad, India). In a similar way, the $\mathrm{Cr}$ (VI) adsorbed nanospheres were also immersed into same volume of water and surface charge was determined.

\section{RESULTS AND DISCUSSION}

(In this section the subheadings should follow the same order than experimental part)

3.1 FTIR Spectra

The Fourier transform infrared (FTIR) spectra of the sodium alginate and calcium alginate nanoparticles were recorded and compared with each other (Fig.1). The FTIR spectra of sodium alginate (Fig. 1(a)) show important absorption bands pertaining to hydroxyl, ether and carboxylic functiona groups. Stretching vibrations of $\mathrm{O}-\mathrm{H}$ bonds of alginate appear in the range of 3000-3600 $\mathrm{cm}^{-1}$. Stretching vibrations of aliphatic C-H were observed at 2920-2850 $\mathrm{cm}^{-1}$. Observed bands at 1649 and $1460 \mathrm{~cm}^{-1}$ were attributed to asymmetric and symmetric vibrations of carboxylate salt ion, respectively.

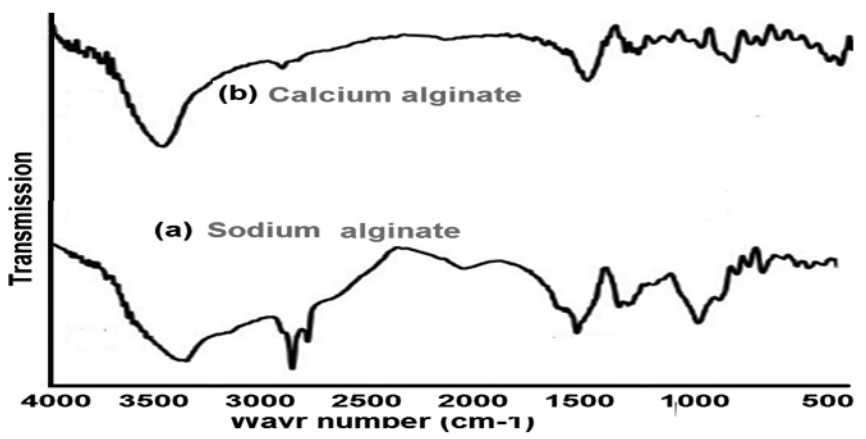

Fig. 1. FTIR spectra of (a) native sodium alginate and (b) calcium crosslinked alginate (nanoparticles).

The bands observed in the spectra after crosslinking with calcium ions are very significant and can be used for characterization of alginate structure. The bands obtained at 1107 and $935 \mathrm{~cm}^{-1}$ were attributed to the $\mathrm{C}-\mathrm{O}$ stretching vibration of pyranosyl ring and the $\mathrm{C}-\mathrm{O}$ stretching with contributions from $\mathrm{C}-\mathrm{C}-\mathrm{H}$ and $\mathrm{C}-\mathrm{O}-\mathrm{H}$ deformation. Calcium alginate nanoparticles powder show significant differences in band positions when compared to the Fourier transform infrared (FTIR) spectrum of sodium alginate (Fig.1.(b)). Absorption region of stretching vibrations of $\mathrm{O}-\mathrm{H}$ bonds in calcium alginate appears narrow than sodium alginate. This difference arises from the participation of hydroxyl and carboxylate groups of alginate to the calcium ion in order to form chelating structure and consequent decrease in hydrogen bonding between hydroxyl functional groups which results in narrowing of bands in calcium alginate. Asymmetric stretching vibration of carboxylate ion shifted to lower wave numbers because when calcium metal ions replace sodium ions in the sodium alginate, the charge density, the radius and the atomic weight of the cations changed and hence, this shifting should be expected.

3.2 SEM Analysis

The morphology of the prepared alginate nanoparticles have been investigated by recording their scanning electrons micrograph as shown in Fig 2. The obtained image clearly reveals that the particles have smooth and regular morphology which is evident from the spherical shape of the nanoparticles. It also reveals from the image that size of the nanoparticles varies between 50 to $350 \mathrm{~nm}$.

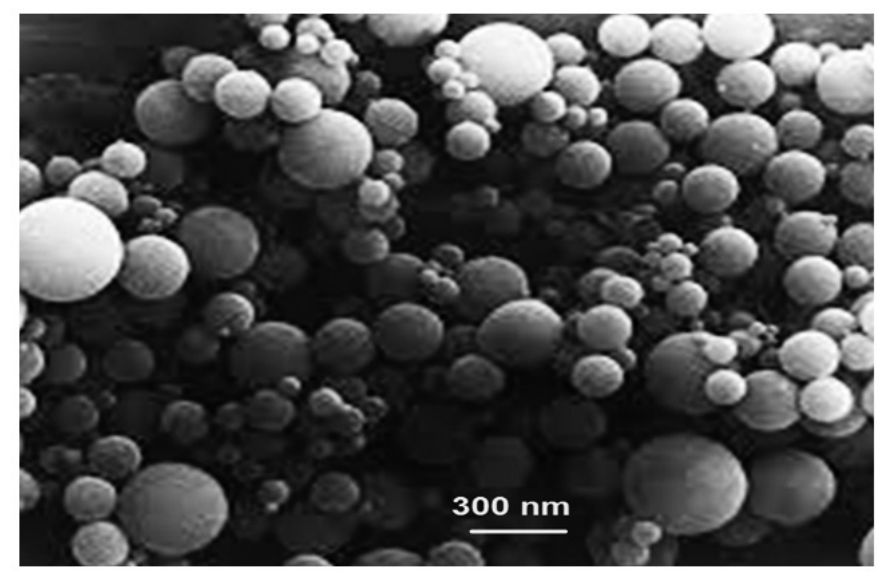

Fig. 2. Scanning electron micrograph (SEM) of calcium crosslinked alginate nanoparticles.

\subsection{Particle Size Analysis}

The particles size analysis of the prepared nanospheres as determined by Dynamic Light Scattering measurements and the size distribution curve is shown in Fig. 3. It is clear from the curve that the nanospheres are heterogeneous in terms of their average size and vary between 30 to $300 \mathrm{~nm}$. It is also revealed by the figure that majority of the particles have dimension of about $100 \mathrm{~nm}$.

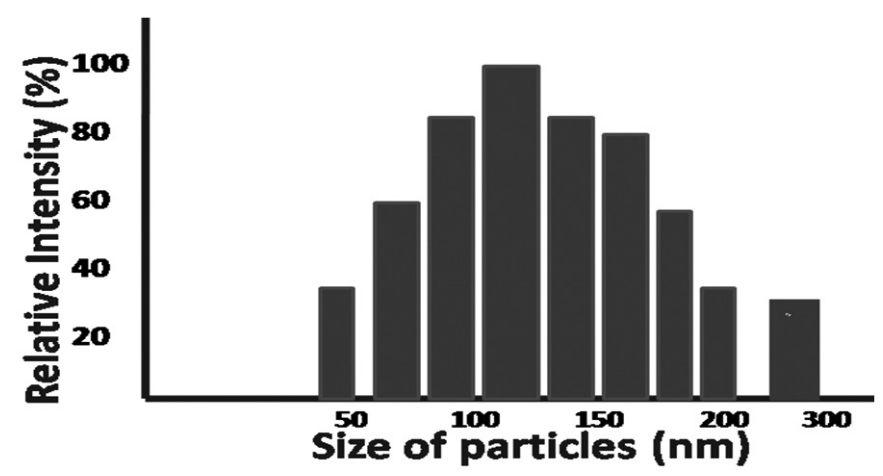

Fig. 3. Particle size distribution curve of calcium alginate nanoparticles.

3.4 Surface charge analysis

The surface charge of the alginate nanoparticles before the adsorption of chromium ions was found to be $28.5 \mathrm{mV}$ which suggests for a stable colloidal dispersion of alginate nanoparticles-water system. After adsorption of chromium ions, the surface charge was found to fall to $21.3 \mathrm{mV}$ which clearly reveals that the chromium ions have been adsorbed onto the surfaces of alginate nanoparticles.

\subsection{Results on adsorption studies}

3.5.1 Effect of metal ion concentration and kinetics

The effect of initial concentration of chromium solution on its adsorption onto prepared alginate nanospheres has been studied by increasing the meta ion concentration in the range 0.5 to $8.0 \mathrm{mg} / \mathrm{L}$ and monitoring the amounts of adsorbed chromium ions over the span of time period up to $60 \mathrm{~min}$. The results are presented in Fig. 4 which clearly reveals that as the time increases, the amount of adsorbed chromium ions also increases and ultimately levels off. It is also clear from the data and Figure that the adsorbed amounts of metal ions also increase with increasing metal ion concentration and ultimately it levels 
off. The results are quite obvious and may be explained by the fact that as the concentration of chromium solution increases, greater number of chromium ions invade the adsorbent surfaces and tend to occupy the active sites available on the nanoparticles surfaces. After almost all the active sites are exhausted, there does not remain a vacant site to bind the metal ions that ultimately leads to saturation of adsorption as indicated by the levelling off of the plots.

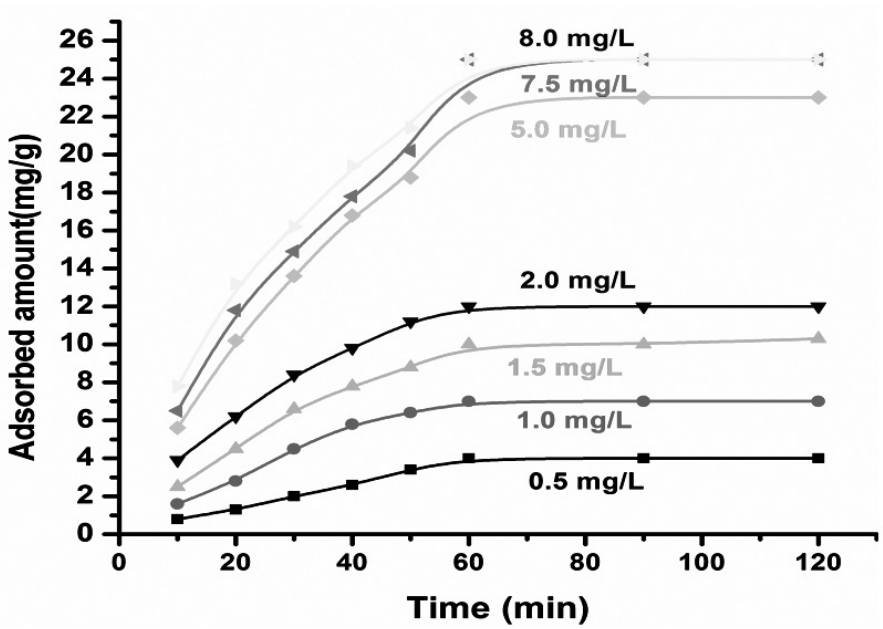

Fig. 4. Graphs showing the variation in the amount of adsorbed $\mathrm{Cr}$ with time at different initial metal ion concentrations.

\subsubsection{Adsorption isotherms}

3.5.2.1 Langmuir model

The effect of equilibrium concentration of metal ions on the amount of the adsorbed chromium ions may quantitatively be dealt with several adsorption isotherm models among which the Langmuir equation has been the most frequently and successfully applied. According the Langmuir equation,

$$
\mathrm{q}_{\mathrm{e}}=\mathrm{q}_{\mathrm{m}} \mathrm{K}_{\mathrm{L}} \mathrm{C}_{\mathrm{e}} / 1+\mathrm{K}_{\mathrm{L}} \mathrm{C}_{\mathrm{e}}
$$

Thus, a plot drawn between the equilibrium concentration and the adsorbed amount depicts a typical type of adsorption isotherm which is a commonly reported isotherm in the literature. More popularly, the equation may also be represented by the following linear form,

$$
\mathrm{Ce} / \mathrm{qe}=1 / \mathrm{q}_{\mathrm{m}} \mathrm{K}_{\mathrm{L}}+\mathrm{C}_{\mathrm{e}} / \mathrm{q}_{\mathrm{m}}
$$

The linearized plot is shown in Fig. $\mathbf{5}$ which clearly indicates that the adsorption data very well follow Langmuir model. The values of adsorption coefficient $\mathrm{K}_{1}$ and adsorption efficiency $\mathrm{q}_{\mathrm{m}}$ have been calculated from the Eq.3 and the values have been found to be 0.34 and $145(\mathrm{mg} / \mathrm{g})$, respectively.

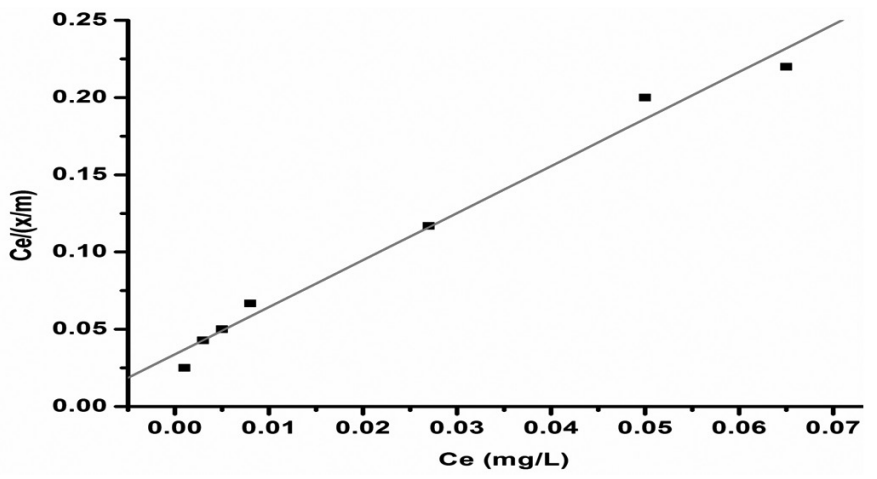

Fig 5. A typical plot drawn in accordance with the linearized Langmuir equation

\subsubsection{Effect of $\mathrm{pH}$}

The $\mathrm{pH}$ seems to be an important parameter in the biosorption processes. It affects the solution chemistry of the metal ion, the activity of the functional groups in the biomass and competition of metallic ions. Cr (VI) exhibits different types of $\mathrm{pH}$ dependence equilibria in aqueous solution. $\mathrm{As} \mathrm{pH}$ is shifted the equilibrium will also shift. The effect of $\mathrm{pH}$ on the adsorbed amount of $\mathrm{Cr}$ (VI) ions have been investigated in the range 2.2 to 9.4 and results are presented in Fig. 6.

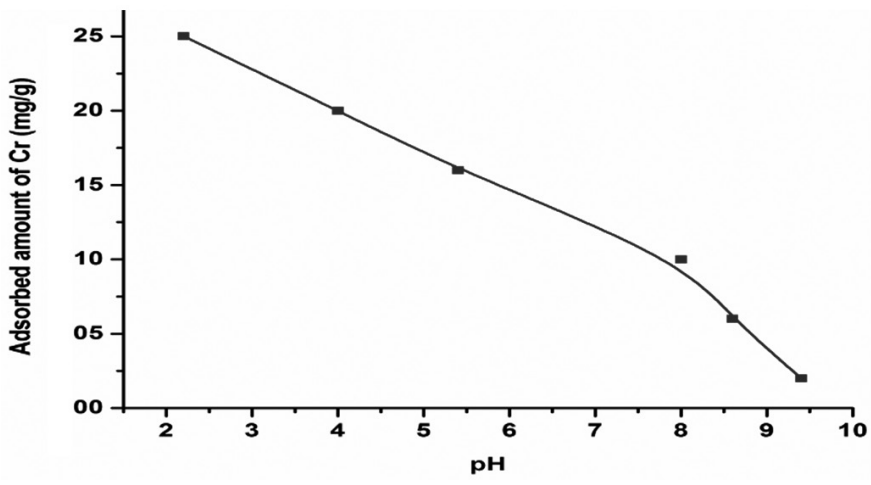

Fig. 6. Effect of $\mathrm{pH}$ on the adsorbed amount of chromium ions.

The results clearly reveal that at low $\mathrm{pH}$ the adsorption is quite high but it decreases with increasing $\mathrm{pH}$ of the solution. The effect of $\mathrm{pH}$ on the adsorption of metal ions on alginate nanoparticles can be attributed to the two main terms, intrinsic adsorption and electrostatic interactions, respectively. The electrostatic term results from the electrostatic energy of interaction between the adsorbent and adsorbate. The charge on substrate as well as softness or hardness of charge on both the sides is mostly responsible for intensity of the interaction. The electrostatic interaction has been observed from adsorption of cationic species versus anionic species on adsorbent [33]. The results suggested that the biosorption of chromium ions to the biomass is mainly due to ion attraction. Therefore, as the $\mathrm{pH}$ decreases, the cell surface becomes more positively charged, thus reducing the attraction between the biomass and metal ions.

The effect of $\mathrm{pH}$ on biosorption of chromium was examined in the $\mathrm{pH}$ range 2.2-9.4. At $\mathrm{pH}$ value more than 9 the chromium ions get precipitated due to high concentration of $\mathrm{OH}^{-}$ions in the adsorption medium and subsequent studies could not be performed. At $\mathrm{pH}$ below 2.2, the poor solubility of sodium alginate is known.

3.5.4 Effect of temperature

The effect of temperature on adsorption is important not only as it affects the rate and extent of adsorption, but also due to the fact that temperature dependence of adsorption provides information about possible adsorbentadsorbate interactions. A typical aspect of adsorption on polymer is that adsorption may increase with increasing temperature, and if so, then adsorption must be entropy rather than energy favoured [34]. In the present work, the effect of temperature on adsorption was studied in the range $10^{\circ} \mathrm{C}-40^{\circ} \mathrm{C}$. The results are shown in Fig. 7 which indicates that adsorption decreases with increasing temperature.

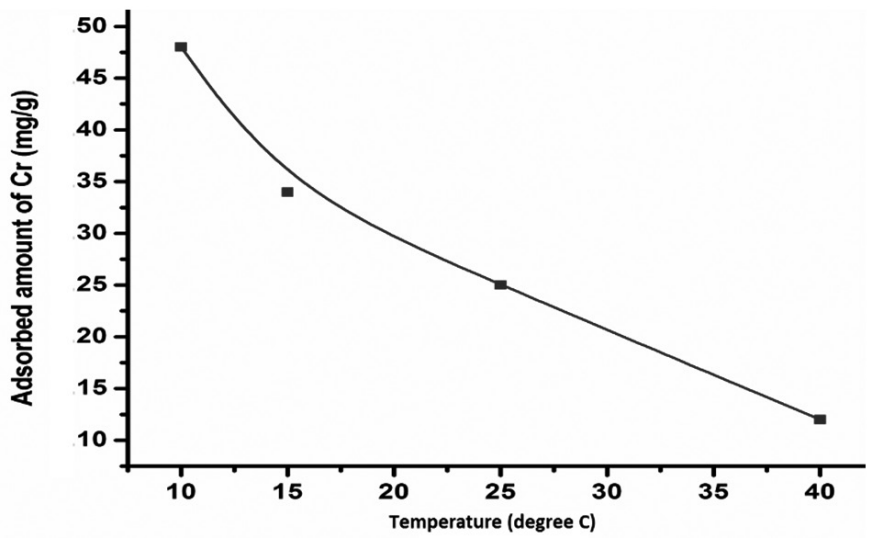

Fig. 7. Effect of temperature on adsorbed amount of chromium.

The decrease in the adsorption of $\mathrm{Cr}$ (VI) ions could be attributed to the 
weakening of the binding forces between $\mathrm{Cr}$ (VI) ions and active sites on the biopolymer nanospheres [35].

The following thermodynamic parameters were calculated by using the following equations [36].

(1) The standard free energy $\Delta \mathrm{G}_{\mathrm{o}}(\mathrm{kcal} / \mathrm{mol})$ was calculated by using the relation

$\Delta \mathrm{G}=-\mathrm{R} \mathrm{T} \ln \mathrm{K}$

where $\mathrm{K}$ being the equilibrium constant at the adsorption process. The value of $\Delta \mathrm{G}$ has been calculated to be $-2.96 \mathrm{kcal} / \mathrm{mol}$.

(2) The apparent heat of reaction enthalpy $\Delta H_{o}(\mathrm{kcal} / \mathrm{mol})$ was calculated using the equation

$\ln \mathrm{k}_{2} / \mathrm{k}_{1}=\Delta \mathrm{H}_{0} / \mathrm{R}\left(1 / \mathrm{T}_{1}-1 / \mathrm{T}_{2}\right)$

where the value of $\mathrm{K}_{1}$ (adsorption coefficient) is 145 at $25^{\circ} \mathrm{C}$, and that of $\mathrm{K}_{2}$ at $40{ }^{\circ} \mathrm{C}$ is 152

The value of $\Delta H$ has been calculated to be $0.251 \mathrm{kcal} / \mathrm{mol}$. The positive value of $\Delta \mathrm{H}_{\mathrm{o}}$ indicates the endothermic nature of adsorption process.

(3) The entropy $\mathrm{S}_{\mathrm{o}}(\mathrm{kcal} / \mathrm{mol})$ of the adsorption process was calculated by the following relationship,

$\Delta \mathrm{G}_{\mathrm{o}}=\Delta \mathrm{H}-\mathrm{T} \Delta \mathrm{S}$

The value $\Delta \mathrm{S}_{0}$ ( $\left.\mathrm{kcal} / \mathrm{mol}\right)$ was found to be $0.010 \mathrm{kcal} / \mathrm{mol}$ which indicates that the adsorption process is spontaneous in nature.

3.5.5 Effect of Adsorbent Dose

The effect of the amount of adsorbent dose on the adsorption of chromium ions has been studied by adding the amount of alginate nanoparticles in the range 50 to $300 \mathrm{mg}$ to the adsorption system .The results are presented in Fig 8 which clearly reveals that the amount of adsorbed chromium ions constantly decreases with increasing dose of the adsorbent. The observed findings may be explained by the fact that with increasing amount of alginate nanoparticles in the metal ion solution, the number of active sites also increases but at the same time the accessibility of metal ions to the active sites get reduced due to crowding of the adsorbent in the suspension. This obviously results in a fall in the amount of adsorbed chromium ions.

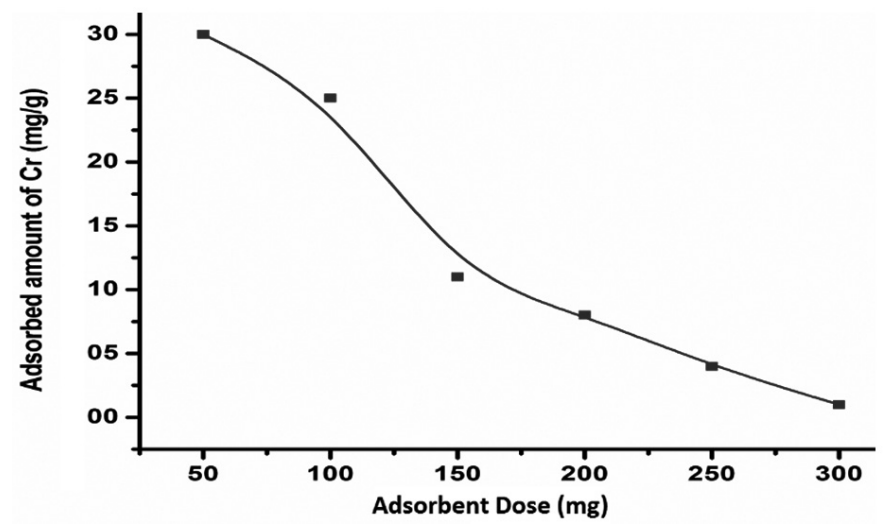

Fig. 8. Effect of adsorbent dose on the adsorption of $\mathrm{Cr}$ ions.

\subsubsection{Effect of composition of nanoparticles}

\subsubsection{Effect of alginate}

The effect of alginate content in the nanoparticles on the adsorption of chromium ions has been investigated by varying the amount of alginate in the range 1.0 to $5.0 \mathrm{~g}$ in the feed mixture of the nanoparticles. The results are shown in the Fig. 9 which clearly reveals a constant fall in the amount of adsorbed chromium ions. The obtained results may be explained by the fact that with increasing amount of alginate, the number of functional groups in the nanoparticles also increases while beyond $1.0 \mathrm{~g}$ alginate content, the nanoparticles network becomes so much compact that diffusion of chromium ions in to the nanoparticle network is restrained which brings about a fall in the adsorbed amount.

\subsubsection{Effect of crosslinker (calcium chloride)}

The number of crosslinks present in the nanoparticles has profound effect on overall properties of the adsorbent material including adsorption capacity. In order to evaluate the effect of concentration of crosslinker on the adsorption of chromium ions, the concentration of calcium chloride was varied in the range 0.3 to $1.0 \mathrm{M}$ and the results are shown in Fig. 10 which clearly show that the adsorption of chromium ions increases with increasing concentration of crosslinker from 0.3 to $1.0 \mathrm{M}$. The results may be explained by the fact that with increasing concentration of calcium chloride the number of crosslinks also increases and due to formation of cage like structure, the chromium ions get more space to enter the nanoparticles network and get adsorbed at the active sites of the nanoparticles network.

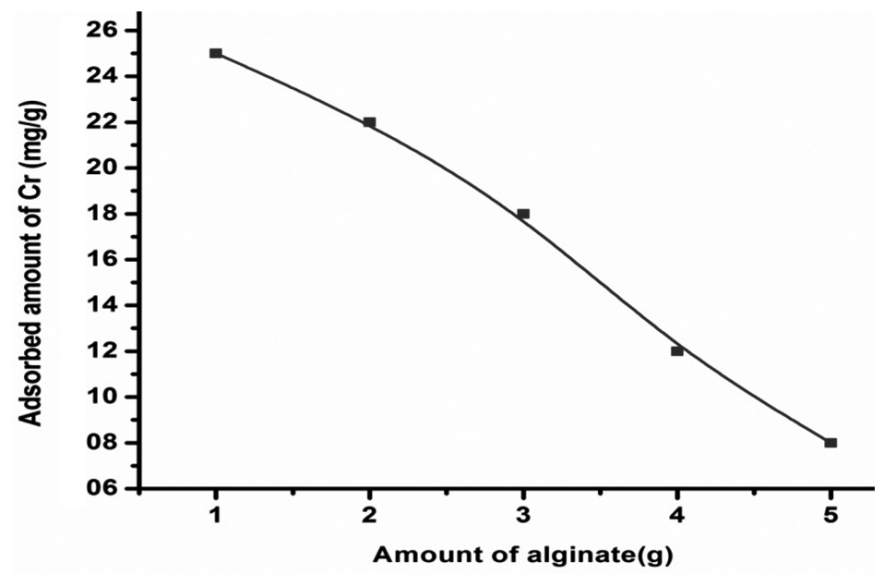

Fig. 9. Effect of alginate on the adsorption of $\mathrm{Cr}$ ions.

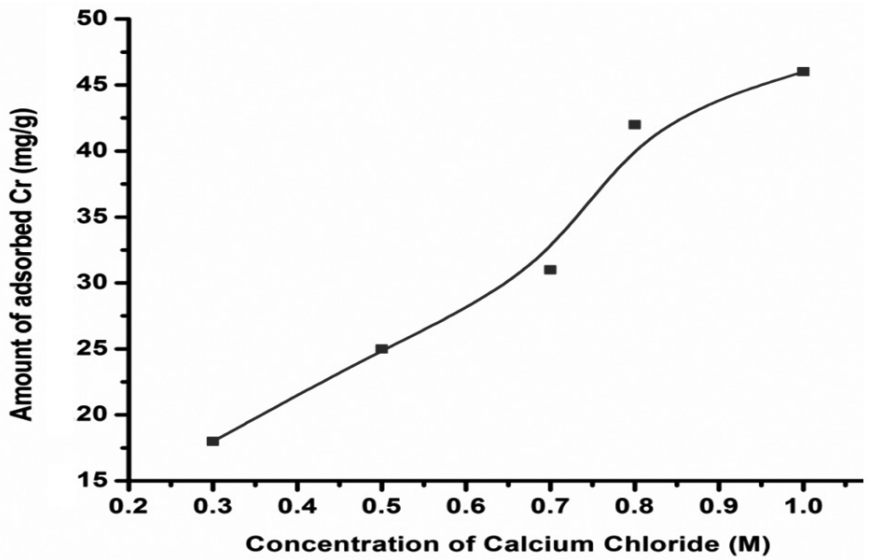

Fig. 10. Effect of crosslinker on the adsorbed amount of $\mathrm{Cr}$ ions.

\section{CONCLUSIONS}

Chemical crosslinking of a water/oil suspension of a sodium alginate produces regular shaped nanospheres having size up to $150 \mathrm{~nm}$. The prepared nanospheres show potential for the removal of chromium ions from aqueous solutions. The alginate nanoparticles were found to exhibit a surface charge of $28.5 \mathrm{mV}$ while after adsorption of chromium ions; it decreased to $21.3 \mathrm{mV}$ thus confirming their adsorption.

The adsorption of chromium ions onto the water-swollen nanospheres increases with increasing initial metal ion concentration in the range 0.5 to 8.0 $\mathrm{mg} / \mathrm{L}$ by monitoring the amounts of adsorbed chromium ions over time period up to $60 \mathrm{~min}$. It is noticed that in the higher concentration range $(8 \mathrm{mg} / \mathrm{L})$ with increasing time, the adsorbed amount tends to level off. It is also clear from the data and the figure that the adsorbed amount of metal ions also increase with increasing metal ion concentration. The adsorption process is found to follow Langmuir adsorption isotherms equation characterized by the appearance of a well marked plateau portion. The adsorbed amount of $\mathrm{Cr}$ ions is significantly affected by $\mathrm{pH}$ of the metal ion solution when varied in the range 2.2 to 9.4. It is noticed that the adsorption initially increases with increasing $\mathrm{pH}$ adsorption gradually decreases. The effect of $\mathrm{pH}$ on chromium was examined in the range 2.2- 9.4. At $\mathrm{pH}$ above 9, the chromium ions get precipitated due to high concentration of $\mathrm{OH}^{-}$ions in the adsorption medium.

The effect of temperature on the adsorption was studied in the range $10^{\circ} \mathrm{C}-40^{\circ} \mathrm{C}$. An optimum amount of chromium ions is adsorbed at $10^{\circ} \mathrm{C}$ while it gradually decreases with increasing temperature.

The adsorption of metal ions varies interestingly with solid to liquid ratio. 
When the volume of metal ion solution at constant solid is decreased, the adsorption is found to increase. On the contrary, an increase in the amount of solid (nanospheres) results in a fall in the metal ion adsorption.

The adsorption of $\mathrm{Cr}$ ions also exhibits a significant change with changing concentration of the nanospheres biopolymer constituents. It is observed that there is a definite concentration of sodium alginate nanoparticles at which the adsorption of $\mathrm{Cr}$ ions is optimum initially but adsorption of metal ions decreases with the increase in dose (sodium alginate nanoparticles).

The adsorption is also influenced by the chemical composition of the nanoparticles. Constant fall in the amount of adsorbed $\mathrm{Cr}$ is noticed with the increase in concentration of alginate. However, on the contrary, with increase in the concentration of cross-linker (calcium chloride), the adsorption of $\mathrm{Cr}$ ions increases.

\section{REFERENCES}

[1] J.N.Moore, S.N. Lumoa, Environ. Sci. Technol. 2, 24 (1990)

[2] H.Akcay, A.Oguz, C.Karapire, Water Res. 813, 37(4) (2003)

[3] P. B Tchounwou, C. G Yedjou, A.K Patlolla and D.J Sutton. HHS Public Access, 101:133-164.(2012)

[4] S.R Mousavi, M balali-Mood, B. Riahi-Zanjani, H. Yousefzadeh, M sadeghi, Int.J. Occup. Env. Med. 4, 2 (2013)

[5] A. Chehregani and B. Malayeri , Int.J.Agri..Biology, 1560, 462(2007)

[6] D.Balamurugan, C.Udayasooriyan, B. Kamaldevi, Int.J.Environ.Sci.5(3), $522(2014)$

[7] P. Miretzky, A.Saralegui, A. F Cirelli, Chemosphere 57, 997 (2004)

[8] V. I. Slaveykova, K. J. Wilkinson, Environ. Sci. Technol. 36, 969 (2002)

[9] E. J. J. Kalis, L. P. Weng, F. Dousma, E. J. M. Temminghoff, W. H. Van Riemsdijk., Environ. Sci. Technol.40, 955 (2006)

[10] H.Sigel (Ed.), Dekker, New York, 24,(1988).

[11] A. Dashti, M. Soodi, N. Amani, Environ. Toxicol.31 (3), 269(2016)

[12] A. Dasht, M. Soodi, N. Amani, Pathobio.Res. 18, 55(2015)

[13] A.Plech, T. Klimkiewicz, H. Jakrzewska, J. Env. Studies, 9(4) 301(2000)
[14] B.A. Adelekan and K.D. Abegunde, Int. J. Phy. Sci. 6, 1045(2011)

[15] R.A Goyer. Mc Graw-Hill Publisher,811 (2001)

[16] P.Saranraj and D.Sujitha International J. Microbiol. Res. 4 (3), 305 (2013)

[17] M Hema, K Srinivasan, Ind. J. Eng. Materl.17, 373 (2010)

[18] R. Taman, M. E. Ossman, M. S. Mansour, H. A. Farag, J. Adv. Chem. Eng. 5, 125(2015)

[19] J.N.Bhakta, P. B. Majumdar, and Y. Munekage, Int.J.Chem.Eng. Vol 201 (2014)

[20] V.Baheti, V.Vellora T. Padil, J. M Cernik, R Mishra. J. Fiber Bioeng. Informatics 6, 175(2013)

[21] K.A. Adegoke, O. S. Bello, Wat.Res.Ind., 12, 8 (2015)

[22] S.K Halnor and M. Ubale, J. Appl. Chem.., 2(3), 475 (2013)

[23] I. Ahmad, S. Zafer, F. Ahmad . J Appl Sci Environ. 9 (1),123 (2005)

[24] G..Donmez. Z. Aksu . Biochemistry, 38(5), 751(2002)

[25] Z. Hu ,L. Lei,Y. Li. And Y. Ni Sep.Purif.Technol. 31(1), 13 (2003)

[26] M. Lotfi And N. Adhoum, Sep.Purif.Technol. 26(2-3), 137(2002)

[27] M. M. Rao, A. Ramesh, G.P.C Rao, K. Seshaiah, J. Hazard Mater, 129, 123 (2006)

[28] M.A.Barakat, Arabian J.Chem. 4, 361 (2011)

[29] A.Padilla, E.L Tavani, Desalination, 129(1-3), 219-226(1999)

[30] M.A Barakat, Jamshed Rashid, M.A Alghamdi., , Seventeenth International water technology conference, IWTC17, Istanbul, 5-7 November 2013.

[31] L.Wu, L. Liao, G. Lv, F. Qin, Y. He, X. Wang, J. Haz. Materials 254,277(2013)

[32] A.K Bajpai, R Sachdeva. J Appl Polym Sci. 78, 1656 (2000)

[33] S.Gang and S. Weixing. Ind. Eng.Chem.Res., 37(4),1324(1998)

[34] A.K Bajpai , N. Vishwakarma Colloids Surface A - Physicochem Eng Aspects ; 220:117(2003)

[35] A K Bajpai, L. Rai.,Ind.J.Chem.Technol. 17, 17 ( 2010)

[36] M.Doula, A.N Loam,A. Dimirkou. Commun Soil Sci Plant Anal. 26:1535. (1995) 